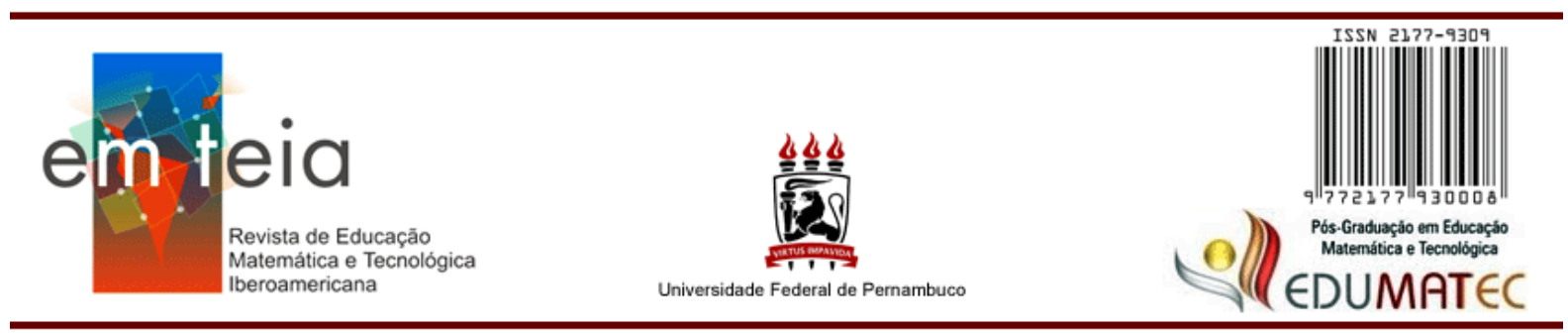

SOFTWARE PIXTON@: uma proposta de recurso para a ilustração

\title{
de possibilidades combinatórias
}

\author{
Dacymere Gadelha \\ Mestre em Educação Matemática e Tecnológica \\ Universidade Federal de Pernambuco - PE - Brasil \\ dacymere@gmail.com \\ https://orcid.org/0000-0002-5025-5779 \\ Rute Borba \\ Doutora em Educação Matemática \\ Universidade Federal de Pernambuco - PE - Brasil \\ resrborba@gmail.com \\ https://orcid.org/0000-0002-5098-4461 \\ Juliana Azevedo Montenegro \\ Doutora em Educação Matemática e Tecnológica \\ Universidade Federal de Pernambuco - PE - Brasil \\ azevedomontenegro.ju@gmail.com \\ http://orcid.org/0000-0003-3570-9581
}

\section{Resumo}

Com o objetivo de investigar o uso do software Pixton $(\mathcal{C}$ para a representação das resoluções de problemas combinatórios, a partir de suas ilustrações pré-definidas, foram analisadas as respostas apresentadas por 12 estudantes do $5^{\mathrm{o}}$ ano do Ensino Fundamental em três etapas. As análises foram estruturadas a partir de três elementos - situações combinatórias, seus invariantes e representações simbólicas utilizadas - para ser verificado o nível de compreensão dos participantes acerca da Combinatória em seus quatro tipos de situações: arranjos, combinações, permutações e produtos de medidas. Percebeu-se uma grande dificuldade em solucionar as oito situações contidas no teste inicial, duas questões de cada tipo. Como proposta de intervenção foram formadas duplas para as sessões de ensino, as quais ocorreram com o uso do Pixton(C) como recurso facilitador na aprendizagem das propriedades combinatórias. Os resultados do teste final, com a mesma estrutura do teste inicial, apontaram que em conformidade com as vivências das sessões de ensino, os estudantes passaram a demonstrar uma melhor compreensão das situações combinatórias. Desse modo, evidencia-se que a maneira como o Pixton $\subset$ foi trabalhado contribuiu para os avanços dos que o manusearam.

Palavras-Chave: Combinatória. Software Pixton(C). Ilustrações. Anos iniciais do Ensino Fundamental.

\footnotetext{
Abstract

In order to investigate the use of Pixton $($ software to represent solutions to combinatorial problems, based on their pre-defined illustrations, the responses presented by 12 students of the 5 th grade of Elementary School, in three stages, were analyzed. The analyses were structured based on three
} 
elements - combinatorial situations, their invariants and symbolic representations used, to verify the level of understanding of the participants about Combinatorics in its four types of situations: arrangements, combinations, permutations and products of measures. It was noticed a great difficulty in solving the eight situations contained in the initial test, two questions of each type. As an intervention proposal, pairs were formed for the teaching sessions, which occurred with the use of Pixton $\odot$ as a facilitating resource in the learning of combinatorial properties. The results of the final test, with the same structure as the initial test, showed that in compliance with the experiences of teaching sessions, students started to demonstrate a better combinatorial understanding. Thus, it is evident that the way Pixton $(\odot$ was worked on contributed to the advances of those who handled it.

Keywords: Combinatorics. Software Pixton@. Illustrations. Elementary School.

\section{Introdução}

O estudo aqui discutido tem como foco a compreensão por estudantes de Anos Iniciais do Ensino Fundamental a respeito de Combinatória - área do conhecimento que está atrelada à ideia de agrupar/combinar elementos de dois ou mais grupos. Discute-se nesse artigo, mais especificamente, como o raciocínio combinatório de crianças em início de escolarização pode ser estimulado por um recurso tecnológico - o software Pixton(C).

O mais recente documento que norteia a escolarização básica, a Base Nacional Comum Curricular - BNCC (BRASIL, 2018), traz em seu texto os conteúdos que são fundamentais para o desenvolvimento das habilidades em cada nível escolar. A BNCC indica que sejam trabalhados, a partir do quarto ano, problemas combinatórios, de um só tipo. Geralmente o contexto dos problemas é o de contagem de conjuntos de roupas que podem ser formados, por exemplo, a partir de um conjunto de quatro blusas, combinado a um conjunto de três saias, o qual pode ser solucionado pela multiplicação dos números de elementos de cada conjunto ( $4 \times 3$, nesse caso).

Entretanto, livros didáticos de Anos Iniciais do Ensino Fundamental apresentam outros tipos de problemas combinatórios e pesquisas diversas (SILVA, 2018; PESSOA; BORBA, 2009, dentre outras) apontam que crianças bem novas possuem início de compreensão dos variados tipos de problemas combinatórios. Assim, recomenda-se que diversificados problemas combinatórios, com resultados com baixo número de possibilidades, sejam trabalhados com crianças desde o início de escolarização.

Problemas combinatórios podem envolver um ou mais conjuntos de elementos, como o problema exemplificado anteriormente, envolvendo dois conjuntos: blusas e saias. As possibilidades são levantadas a partir da escolha de elementos desses conjuntos. Em alguns dos problemas, a ordenação dos elementos implica em possibilidades distintas e, em outros, não. Além dessas relações - de escolha e de ordenação dos elementos - os problemas 
combinatórios possuem em comum a propriedade de esgotamento de todas os diferentes modos dos elementos serem combinados.

Quanto às maneiras de resolver problemas combinatórios, há desde as estratégias mais informais - a exemplo das ilustrações dos elementos em desenho - às mais formais, envolvendo o uso de fórmulas matemáticas. Para os anos iniciais do Ensino Fundamental não há a pretensão de serem trabalhadas estratégias formais, mas, sim, o de viabilizar os meios mais fáceis das crianças compreenderem variadas situações combinatórias.

Para a proposta de problemas combinatórios simples, na BNCC é indicado o uso do “suporte de imagem e/ou material manipulável” (BRASIL, 2018, p. 289). Na seção que segue são apresentados estudos anteriores que utilizaram alguns desses recursos, entre outros, para a resolução de problemas combinatórios por parte de estudantes, em particular os de Anos Iniciais do Ensino Fundamental.

Para Chamorro (2003, p. 257), "todos os recursos que sejam criados, produzidos e aplicados na ação educativa e que promovam o desenvolvimento do processo cognitivo são recursos que servem de apoio ao professor enquanto leciona”. Portanto, entende-se que os recursos didáticos são, quando bem direcionados, facilitadores que contribuem com o trabalho do professor por viabilizar a compreensão dos estudantes que os manuseiam.

Com base em outras pesquisas, mediante o entendimento das possíveis contribuições e relevância dos recursos didáticos para a compreensão da Combinatória, foi investigado o software Pixton(C). Na presente pesquisa, a investigação ocorreu na resolução de problemas combinatórios durante sessões de ensino realizadas com estudantes do $5^{\circ}$ ano do Ensino Fundamental.

A escolha desse recurso - Pixton $(\mathcal{C}$ - se deu por conta das ilustrações disponibilizadas, permitindo a representação de variadas formas de combinar elementos. É importante destacar que as funcionalidades desse software foram repensadas para contextos da Combinatória, pois a sua finalidade inicial é a de criar histórias em quadrinhos (HQ). Veremos, a seguir, como esse software foi utilizado para a resolução de situações combinatórias.

\section{Recursos utilizados em estudos anteriores}

Pesquisas anteriores apresentam a possibilidade do trabalho combinatório com recursos didáticos desde a Educação Infantil. A seguir serão mencionados os principais resultados de alguns desses estudos. 
Leite, Pessoa, Ferraz e Borba (2009) ${ }^{1}$ investigaram dois softwares e três Objetos de Aprendizagem (OA), desenvolvidos para facilitar a compreensão de situações combinatórias. As pesquisadoras utilizaram algumas técnicas de análise para verificar as possíveis contribuições e/ou limitações dos recursos. Foram descritas as principais funcionalidades de três Objetos de Aprendizagem - Combinação (RIVED, 2008); Permutação (RIVED, 2008) e Arranjo (RIVED, 2008). Dos pontos positivos apresentados, destacam-se: a proposta de problemas contextualizados em cenários visualmente atrativos e relacionados ao contexto dos problemas. Porém, uma limitação percebida é a que ocorre durante a construção dos agrupamentos: a ação é interrompida por uma janela que exibe a forma pela qual o problema pode ser solucionado fazendo uso da fórmula matemática, não permitindo ser finalizado de outra maneira o raciocínio do participante. Dos dois softwares avaliados, o Árbol (AGUIRRE, 2005) se aproximou mais das expectativas traçadas, tendo em vista a possibilidade de serem trabalhados diferentes tipos de situações combinatórias a partir da construção de árvores de possibilidades que podem ser coloridas e ajustadas de acordo com o tipo de problema. Os resultados desse estudo apontam a necessidade de serem repensados ou criados mais recursos tecnológicos que atendam as relações e propriedades trabalhadas na Combinatória e que estejam de acordo com o nível escolar dos estudantes.

Azevedo $(2013)^{2}$ desenvolveu um estudo com estudantes do $5^{\circ}$ ano do Ensino Fundamental divididos em dois grupos experimentais: G1 (uso do software Árbol); G2 (uso do lápis e papel). Ambos os grupos foram instruídos na construção de árvores de possibilidades, mas por meios distintos - no computador (utilizando-se das construções efetuadas pelo software) ou no papel (com as construções efetuadas pelas crianças). Os resultados indicaram que os participantes dos dois grupos demonstraram avanços em seus raciocínios combinatórios, com um desempenho um pouco melhor do G2. Concluiu-se que os dois recursos testados podem ser propostos articuladamente para os estudantes do Ensino Fundamental como facilitadores na compreensão da Combinatória.

Silva $(2018)^{3}$ investigou a compreensão da Combinatória por crianças da Educação Infantil. Parte das crianças trabalhou com fichas ilustrativas (dos elementos mencionados nos enunciados dos problemas) e outra parte das crianças produziu desenhos. Ambos os recursos

\footnotetext{
${ }^{1}$ https://docs.google.com/file/d/0B3nOb_rG1DUhak1nbXBBRW1KaVU/edit

${ }^{2}$ https://drive.google.com/file/d/0B3nOb rG1DUhY2tfMUtBRGN6LXM/edit

${ }^{3}$ https://drive.google.com/file/d/13a4jPyl2AKdi1YRinffQyzpiRNLsR669/view
} 
possibilitaram observar início de compreensões das situações combinatórias tratadas, sendo as fichas de mais rápido manuseio, uma vez que todos os elementos estavam prontos para uso.

As pesquisas aqui relatadas permitem concluir que recursos variados - tecnológicos, ou não - podem ser usados no estudo da Combinatória com estudantes, em particular os em início de escolarização. No presente estudo se discute, na seção que segue, outra possibilidade de recurso e, em seguida, são apresentados os principais fundamentos teóricos da pesquisa em tela.

\section{Software Pixton@}

O Pixton@ é um programa cujo acesso se dá em conexão com a internet, e o login através de contas logadas (Google, Facebook e Microsoft) no aparelho em uso, ou, no preenchimento de dados para a criação de uma conta. As informações do Pixton@ podem ser traduzidas facilmente nas ferramentas do navegador utilizado, caso não estejam no idioma português. Nesse software são apresentadas três opções com finalidades para a construção de HQ, sendo elas: educação, entretenimento e negócios, nas quais são disponibilizados modelos de produções divulgadas por vários participantes. No primeiro acesso o usuário precisa optar entre os pacotes de custo, para ter uma variedade maior de edições, ou a versão gratuita que é mais limitada.

Para o objetivo desse estudo, a opção de gratuidade foi suficiente para a ilustração de possibilidades combinatórias e sem a necessidade de serem inseridos balões de diálogos. Todas as construções ficaram salvas na conta de acesso da pesquisadora para facilitar as análises feitas posteriormente. Segue-se discussão referente às situações combinatórias tratadas por uso do software Pixton@.

\section{Problemas combinatórios e a Teoria dos Campos Conceituais}

A Combinatória faz parte de atividades diárias, mas nem sempre nos damos conta de todas as possibilidades envolvidas em cada situação, geralmente por não haver a necessidade de quantificar todas as maneiras de escolhas, devido ao fato de serem selecionadas as que são de preferência de cada um. No entanto, para que seja amplamente desenvolvido o raciocínio combinatório, é preciso que as variadas relações e propriedades desses tipos de problemas sejam consideradas no ensino desse conteúdo. 
São quatro os tipos de situações combinatórias organizados por Borba (2010) em uma categorização conjunta: arranjo, combinação, permutação e produto de medidas. Nessas situações devem ser consideradas a escolha e a ordenação dos elementos, bem como o esgotamento de possibilidades, de acordo com cada tipo, conforme descrito a seguir e exemplificado no Pixton $\mathbb{C}$.

\section{Arranjo}

Neste tipo de situação, de um conjunto único são escolhidos alguns elementos e a ordenação dos mesmos implicará em diferentes possibilidades. Como exemplo tem-se: Em uma festa junina há três participantes (Arthur, Lucas e Renê) concorrendo aos títulos de Rei do Milho e Príncipe do Milho. Quantas são as possibilidades de termos um vencedor para o Rei e um para Príncipe? Na Figura 1 tem-se uma possível ilustração da solução desse problema com indicação das seis possibilidades (Arthur e Lucas); (Arthur e Renê); (Lucas e Arthur); (Lucas e Renê); (Renê e Arthur); (Renê e Lucas).

Figura 1 - Ilustração das possibilidades de um problema de arranjo no Pixton(C

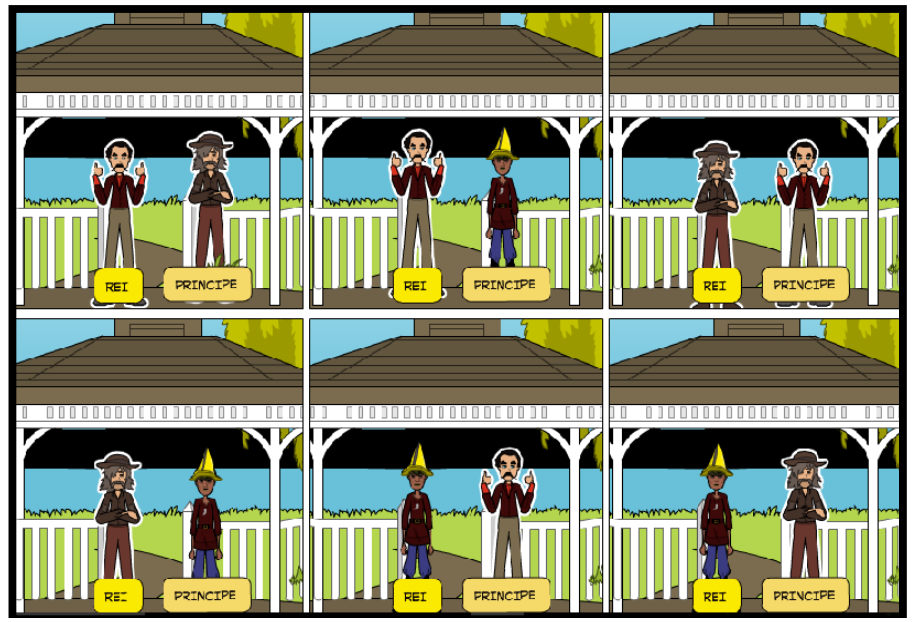

Fonte: Pixton $\subset(2020)$.

\section{Combinação}

Neste tipo de situação, a escolha dos elementos também se dá a partir de um conjunto maior, porém, a ordenação dos elementos não indicará possibilidades distintas. Um exemplo de combinação é: No restaurante Capitão Gancho em cada mesa o garçom precisará optar por dois itens dentre três (maionese, ketchup e molho especial) para serem disponibilizados aos clientes. Quantas são as possibilidades de serem definidos os itens de uma mesa? Na Figura 2 
tem-se uma ilustração da situação, com a indicação da resposta: três possibilidades (maionese e ketchup); (maionese e molho especial); (ketchup e molho especial).

Figura 2 - Ilustração das possibilidades de um problema de combinação no Pixton(C

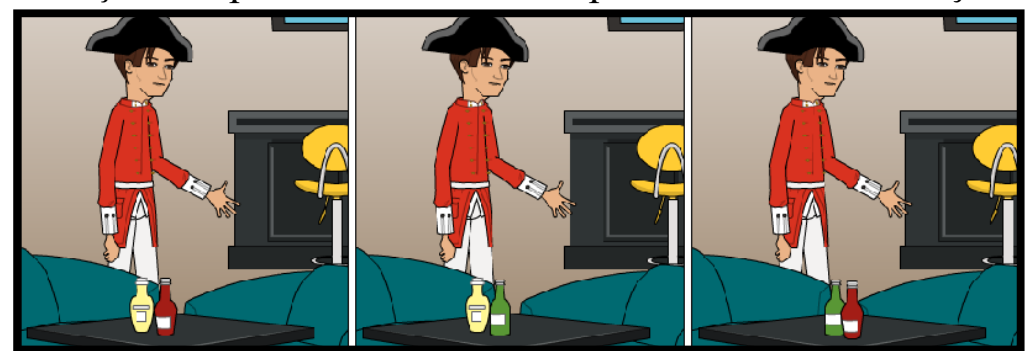

Fonte: Pixton® (2020).

\section{Permutação}

Neste tipo de situação, todos os elementos são agrupados simultaneamente e a ordenação dos elementos indica diferentes possibilidades. Tem-se como exemplo: Ravi selecionou três números (3, 7 e 9) para criar placas diferentes para seus carrinhos. Quantas são as possibilidades que Ravi tem de formar uma placa contendo os três números indicados? $\mathrm{Na}$ Figura 3 ilustra-se a solução das seis possibilidades (3-7-9); (3-9-7); (7-3-9); (7-9-3); (9-3-7); $(9-7-3)$.

Figura 3 - Ilustração das possibilidades de um problema de permutação no Pixton $\subset$

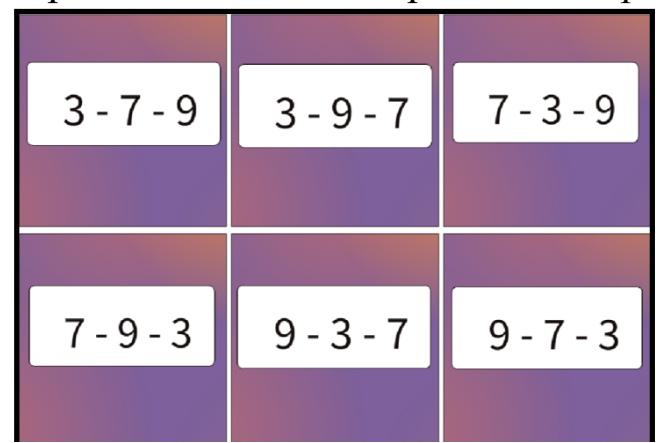

Fonte: Pixton® (2020).

\section{Produto de medidas}

Esse tipo de situação envolve dois ou mais conjuntos de elementos, os quais são agrupados, um de cada conjunto, sem haver a necessidade de reposicioná-los, pois a ordenação nesse caso não indica distintas possibilidades. Um exemplo desse tipo de problema é: Marina pretende comprar um aquário e um peixinho. Na loja há disponíveis duas opções de aquários (retangular e arredondado) e três cores de peixinhos (azul, laranja e vermelho). Quantas são as possibilidades de comprar um aquário e um peixinho? A Figura 4 ilustra a resposta esperada: seis possibilidades (aquário retangular e peixinho azul); (aquário retangular 
e peixinho laranja); (aquário retangular e peixinho vermelho); (aquário arredondado e peixinho azul); (aquário arredondado e peixinho laranja); (aquário arredondado e peixinho vermelho).

Figura 4 - Ilustração das possibilidades de arranjo no Pixton (

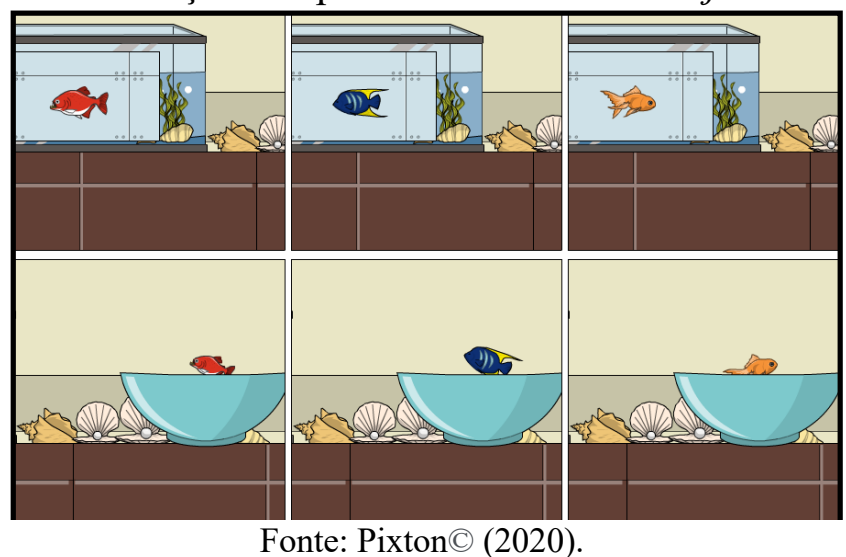

Entende-se que para o processo de compreensão das situações combinatórias mencionadas, se faz necessário analisar três aspectos: as situações que dão sentido à Combinatória $(S)$, os invariantes dessas situações (I) e as representações simbólicas $(R)$ utilizadas. Estes aspectos constituem o tripé defendido por Vergnaud (1996) em sua Teoria dos Campos Conceituais (TCC), como indicado na Figura 5.

É possível verificar que as situações $(S)$, as quais dão significado à Combinatória, dizem respeito à variedade de problemas que assumem diferentes relações, mas que englobam uma mesma forma de pensar, nesse caso, o raciocínio combinatório. Os invariantes (I) retratam as singularidades das distintas situações e as representações simbólicas $(R)$ indicam modos de registrar as situações. De acordo com a TCC, enfatiza-se a necessidade de serem exploradas situações em suas variedades, bem como distintos modos de representá-las.

Figura 5 - Tripé da formação dos conceitos, segundo a TCC, relacionado à Combinatória.

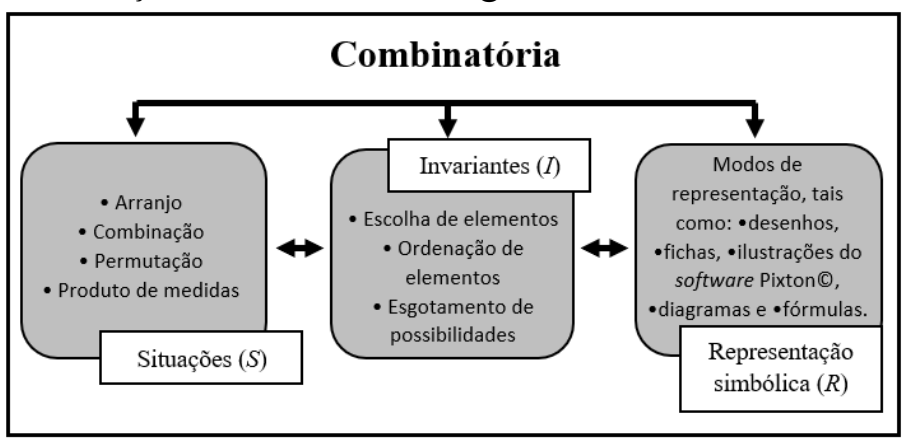

Fonte: Autoras mediante pesquisa (VERGNAUD, 1996). 


\section{Método adotado no estudo}

A realização da pesquisa aqui relatada (GADELHA, 2020) contou com a participação de 36 estudantes do $5^{\circ}$ ano do Ensino Fundamental de duas escolas municipais da rede pública do Recife. No entanto, foram analisados no presente texto apenas os resultados dos 12 estudantes que fizeram parte do grupo que manuseou o software Pixton $\complement^{4}$.

A pesquisa foi estruturada em três etapas: teste inicial, sessões de ensino e teste final. Os testes continham oito problemas combinatórios, sendo dois de cada tipo de situação arranjo, combinação, permutação e produto de medidas -, variando entre 04 a 12 possibilidades como resposta, solucionados com lápis e papel. No Quadro 1 é possível observar como o teste inicial foi estruturado.

Quadro 1 - Teste inicial por tipo de situação e total de possibilidades

\begin{tabular}{|c|c|c|}
\hline Tipo & Situação-problema & Total \\
\hline Arranjo & $\begin{array}{l}\text { Três amigos (Beto, Liz e Chico) apostaram corrida na praia de } \\
\text { Boa Viagem. De quantas maneiras diferentes se pode ter o } \\
\text { primeiro e o segundo lugares? }\end{array}$ & 06 \\
\hline Combinação & $\begin{array}{l}\text { D. Marta levou seus quatro filhos (Bianca, Sabrina, Diego e } \\
\text { Felipe) ao parque e no brinquedo pula-pula só podem entrar } \\
\text { três crianças por vez. De quantas maneiras diferentes três } \\
\text { crianças brincarão por vez no pula-pula? }\end{array}$ & 04 \\
\hline Permutação & $\begin{array}{l}\text { Três irmãos (Igor, Léo e Tina) querem se sentar nos três } \\
\text { últimos lugares disponíveis no cinema. De quantas maneiras } \\
\text { diferentes os três irmãos podem se sentar nos lugares } \\
\text { disponíveis? }\end{array}$ & 06 \\
\hline $\begin{array}{l}\text { Produto de } \\
\text { medidas }\end{array}$ & $\begin{array}{l}\text { Na loja Quero Mais estão disponíveis três tipos de botas } \\
\text { (marrom, preta e vinho) e dois tipos de gorros (cinza e rosa). } \\
\text { De quantas maneiras diferentes pode-se comprar uma bota e } \\
\text { um gorro? }\end{array}$ & 06 \\
\hline Arranjo & $\begin{array}{l}\text { Há quatro alunos (César, Lay, Bete e Luan) concorrendo ao } \\
\text { cargo de representante e vice representante. De quantas } \\
\text { maneiras diferentes podem ser escolhidos um representante e } \\
\text { um vice representante? }\end{array}$ & 12 \\
\hline Combinação & $\begin{array}{l}\text { Na barraca Espaço Drinks há cinco frutas (acerola, caju, } \\
\text { laranja, limão e maracujá) e os sucos são preparados } \\
\text { misturando duas das frutas. De quantas maneiras diferentes os } \\
\text { sucos podem ser preparados com duas frutas? }\end{array}$ & 10 \\
\hline Permutação & $\begin{array}{l}\text { Na prateleira da casa de Edson estão três objetos (uma bola de } \\
\text { futebol, um troféu e uma bola de basquete). De quantas }\end{array}$ & 06 \\
\hline
\end{tabular}

${ }^{4}$ Os demais participantes foram divididos em outros dois grupos com o mesmo número de crianças: um grupo experimental que manuseou fichas ilustrativas nas sessões de ensino e um grupo controle que só realizou os testes com lápis e papel. Os três grupos foram emparelhados a partir dos resultados do teste inicial, de modo, que partissem de pontuações próximas. A proposta de ter dois grupos experimentais que manuseassem diferentes recursos nos momentos de ensino teve como objetivo verificar as contribuições e limitações de cada um. 


\begin{tabular}{|c|l|c|c|}
\hline & $\begin{array}{l}\text { maneiras diferentes ele pode colocar os três objetos lado a lado } \\
\text { na prateleira? }\end{array}$ & & 12 \\
\hline $\begin{array}{c}\text { Produto de } \\
\text { medidas }\end{array}$ & $\begin{array}{l}\text { Na lanchonete Oba-oba há quatro sabores de suco (graviola, } \\
\text { laranja, morango e uva) os quais são servidos em copos de três } \\
\text { tamanhos (pequeno, médio e grande). De quantas maneiras } \\
\text { diferentes pode-se tomar um suco de um sabor em um } \\
\text { tamanho de copo? }\end{array}$ & & \\
\hline
\end{tabular}

Fonte: Gadelha (2020).

Nas quatro primeiras situações estavam as que tinham o total de possibilidades mais reduzido e as últimas com maior número de possibilidades, mas no máximo com 12 possibilidades, com exceção nas situações de permutação, pois o acréscimo de mais um elemento no enunciado da questão chegaria a 24 possibilidades.

A partir dos resultados do teste inicial, foram formadas seis duplas, cada uma participando de duas sessões de ensino, em dias distintos, com duração aproximada de 1 hora e 30 minutos cada.

Durante as sessões de ensino foram resolvidos os problemas do teste inicial. No primeiro dia ocorreu a familiarização com o Pixton $\mathbb{C}$, sendo apresentadas as ferramentas e o passo a passo de acesso para a construção das ilustrações no notebook. Em seguida, foi proposto que os estudantes solucionassem as quatro primeiras questões diretamente no Pixton $($, com uma maior mediação da pesquisadora. No segundo dia, foram solucionadas as demais questões do teste, dando mais autonomia à dupla de crianças. Como etapa final, os estudantes realizaram o segundo teste sem o auxílio do Pixton@

\section{Análise e discussão de resultados}

\section{Teste inicial}

No Quadro 2 é apresentada a classificação da pontuação atribuída às respostas nos testes, a qual baseou-se nas relações de escolha e ordenação das situações combinatórias, bem como na propriedade em comum a todas as situações, ou seja, o esgotamento das possibilidades.

Quadro 2 - Classificação das respostas

\begin{tabular}{|c|c|c|}
\hline Classificação & Tipo de resposta & Pontuação \\
\hline Incorreta & $\begin{array}{c}\text { Escolha incorreta; ordenação incorreta; sem } \\
\text { esgotamento das possibilidades. }\end{array}$ & $\mathbf{0}$ \\
\hline Acerto parcial I & $\begin{array}{c}\text { Escolha adequada, mas limita-se a uma } \\
\text { possibilidade. }\end{array}$ & $\mathbf{1}$ \\
\hline Acerto parcial II & Escolha adequada, mas apresenta número & $\mathbf{2}$ \\
\hline
\end{tabular}




\begin{tabular}{|c|c|c|}
\hline & de possibilidades limitado ao número de elementos. & \\
\hline Acerto parcial III & Escolha adequada, ordenação incorreta. & $\mathbf{3}$ \\
\hline Acerto parcial IV & $\begin{array}{c}\text { Escolha correta ou adequada e ordenação } \\
\text { correta, esgotamento das possibilidades incorreto. }\end{array}$ & $\mathbf{4}$ \\
\hline Acerto total & $\begin{array}{c}\text { Escolha correta, ordenação correta e } \\
\text { esgotamento das possibilidades. }\end{array}$ & $\mathbf{5}$ \\
\hline
\end{tabular}

Fonte: Gadelha (2020).

$\mathrm{Na}$ Tabela 1 são apresentados os resultados obtidos no teste inicial, por tipo de situação e por classificação de resposta.

Tabela 1 - Percentual de acertos no teste inicial, por tipo de situação e tipo de resposta

\begin{tabular}{|c|c|c|c|c|c|c|}
\cline { 2 - 7 } \multicolumn{1}{c|}{} & Incorreta & $\begin{array}{c}\text { Acerto } \\
\text { Parcial I }\end{array}$ & $\begin{array}{c}\text { Acerto } \\
\text { Parcial } \\
\text { II }\end{array}$ & $\begin{array}{c}\text { Acerto } \\
\text { Parcial } \\
\text { III }\end{array}$ & $\begin{array}{c}\text { Acerto } \\
\text { Parcial } \\
\text { VI }\end{array}$ & $\begin{array}{c}\text { Acerto } \\
\text { Total }\end{array}$ \\
\hline Arranjo & 75,0 & 4,1 & --- & --- & 20,8 & 12,5 \\
\hline Combinação & 66,6 & 8,3 & 4,1 & 8,3 & 12,5 & --- \\
\hline Permutação & 58,3 & 26,6 & --- & --- & --- & --- \\
\hline $\begin{array}{c}\text { Produto de } \\
\text { Medidas }\end{array}$ & 62,5 & 16,7 & 12,5 & --- & 8,3 & 4,1 \\
\hline
\end{tabular}

Fonte: Gadelha (2020).

Quantitativamente, é possível perceber que na primeira etapa da pesquisa boa parte das respostas não apresentava relação combinatória e, por isso, foram classificadas como incorretas, sendo as mais recorrentes, ultrapassando $50 \%$ em cada tipo de situação. Verifica-se que apenas nas situações de arranjo e produto de medidas foram tidos raros casos de acerto total e nas demais situações alguns poucos acertos parciais.

A seguir serão apresentados alguns exemplos de respostas no primeiro teste, os quais denotam as dificuldades inicialmente apresentadas pelos estudantes. A categorização de resposta incorreta foi mais frequente nos problemas de arranjo nos quais nenhum dos invariantes combinatórios foi considerado. Na Figura 6 tem-se um exemplo de ausência de relação combinatória na solução dada ao problema. 
Figura 6 - Resposta classificada como Incorreta no teste inicial

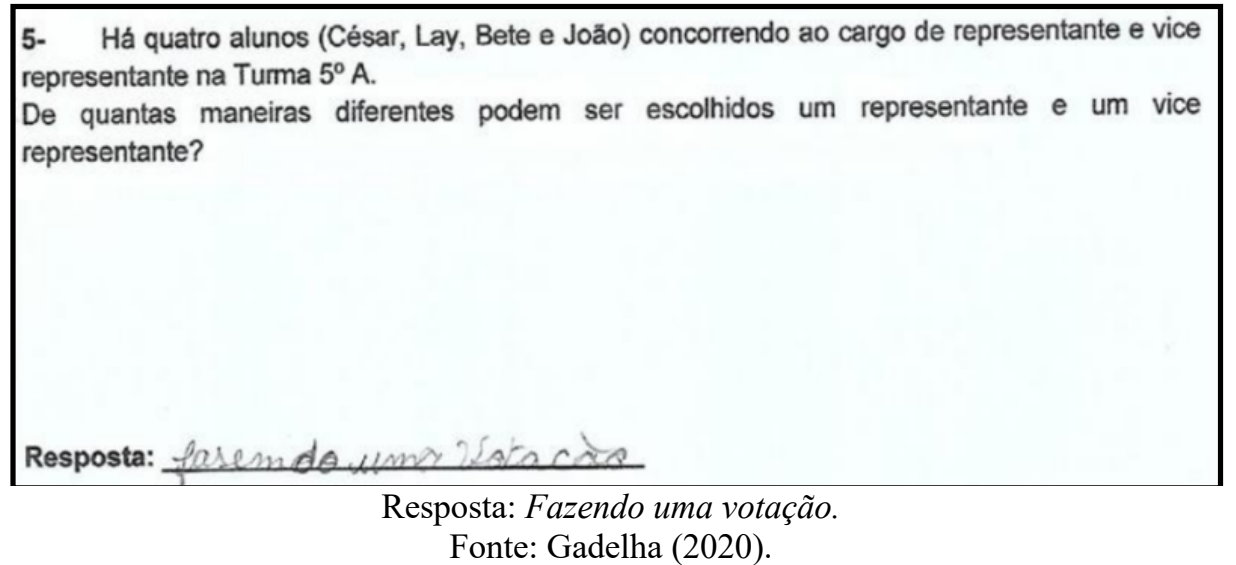

Outro tipo de resposta frequente no teste inicial foi a apresentação de apenas uma possibilidade, como indicado na Figura 7.

Figura 7 - Resposta classificada como Acerto Parcial I no teste inicial

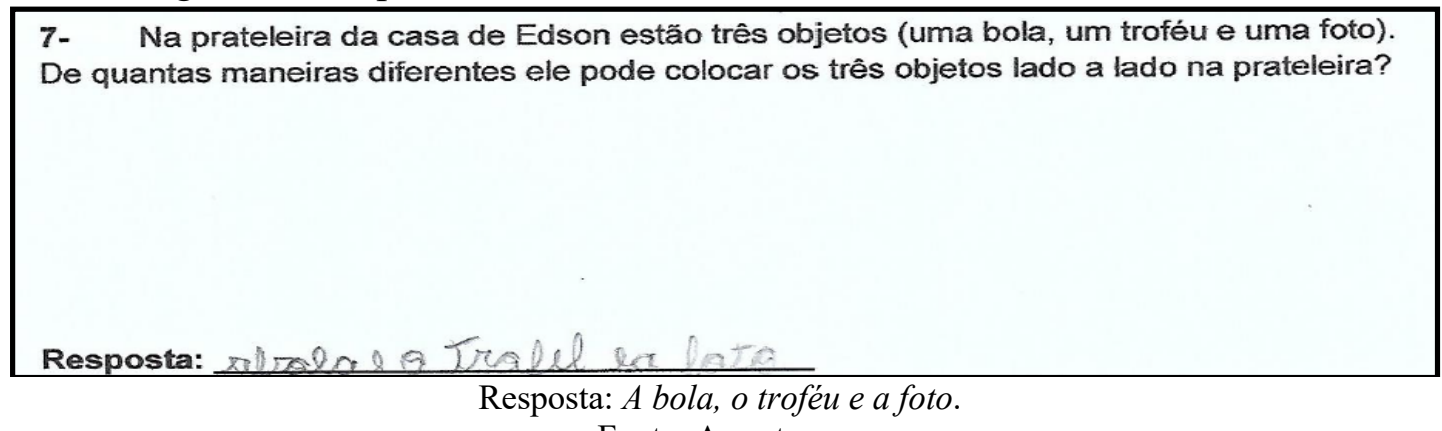

Fonte: As autoras

A princípio, permutação foi o que se mostrou mais difícil para os estudantes. Neste tipo de problema, o único nível de acerto contemplado foi o de Acerto Parcial I. Neste tipo de problema todos os elementos são escolhidos simultaneamente, mas ordenados diferentemente. Isso pode ter levado os estudantes a suporem que uma única possibilidade construída fosse suficiente, já que todos os elementos foram envolvidos na resposta.

Logo, percebe-se que a maior parte dos estudantes incialmente apresentava alguma dificuldade na compreensão dos problemas combinatórios, embora alguns mostrassem princípios de compreensão combinatória. Com isso em mente, foram realizadas as sessões de ensino, descritas a seguir.

\section{Sessões de ensino}

No primeiro momento, com cada dupla, foi apresentado o software Pixton $\bigodot$ e como proceder para a elaboração das ilustrações em quadrinhos. Os participantes puderam dispor 
das opções de edição e manuseá-las livremente por alguns instantes. Em seguida, foi proposto que fizessem uso de tais ferramentas para representarem a solução da primeira questão do teste inicial.

Ao longo das sessões de ensino os estudantes foram confrontados com questionamentos referentes à escolha dos elementos (de um conjunto ou de mais de um conjunto), à ordenação dos elementos (se resultava, ou não, em possibilidades distintas) e se todas as possibilidades haviam sido encontradas (esgotadas).

Na Figura 8 é possível verificar como as possibilidades foram ilustradas no Pixton@ por uma das duplas na primeira questão. Nessa produção é visto que cada possibilidade foi construída em um quadrinho, logo, têm-se como resultado seis diferentes maneiras de serem classificados os dois primeiros lugares.

Figura 8 - Ilustração de uma solução apresentada na primeira sessão de ensino com o uso do Pixton(

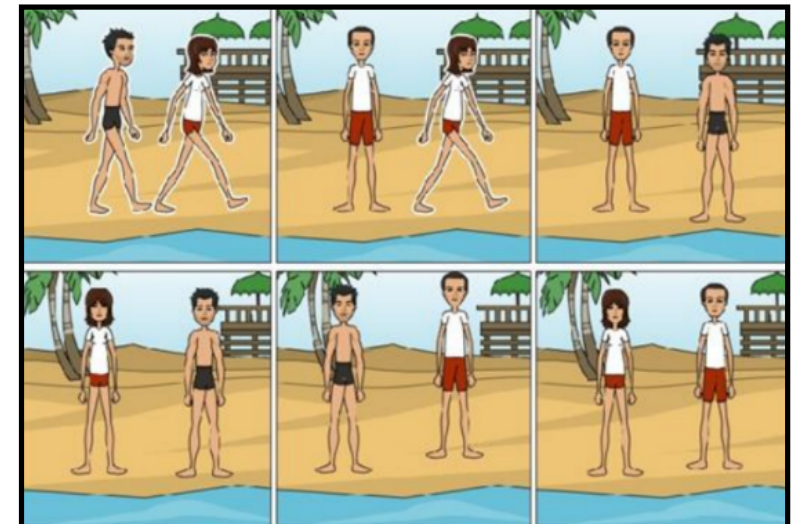

"Situação de arranjo - Três amigos (Beto, Liz e Chico) apostaram corrida na praia de Boa Viagem. De quantas maneiras diferentes se pode ter o primeiro e o segundo lugares?"

Fonte: Gadelha (2020).

Pode-se notar que para essa representação os participantes tiveram o cuidado de localizar um cenário de fundo que estivesse de acordo com o contexto do enunciado da questão. No entanto, todos haviam sido informados que não seria preciso se ater a esses detalhes, no caso de não ser localizado algum objeto de seu interesse.

O trabalho em dupla foi um aspecto bastante positivo, pois, com o andamento das resoluções do teste inicial, os participantes se ajudavam mutuamente na percepção de algum equívoco e/ou na compreensão do problema. No último problema de combinação, por exemplo, era questionado quais as diferentes maneiras de se escolher duas dentre cinco frutas. Um dos participantes iniciou a resolução inserindo todas as cinco frutas no primeiro quadrinho. O seu colega lhe alertou que uma vez que uma das frutas fosse combinada com as 
demais a mesma não poderia ser repetida com nenhuma outra fruta. Na Figura 9, é apresentado como os estudantes consolidaram essa linha de raciocínio.

Figura 9 - Ilustração (editada) da solução apresentada na segunda sessão de ensino com o uso

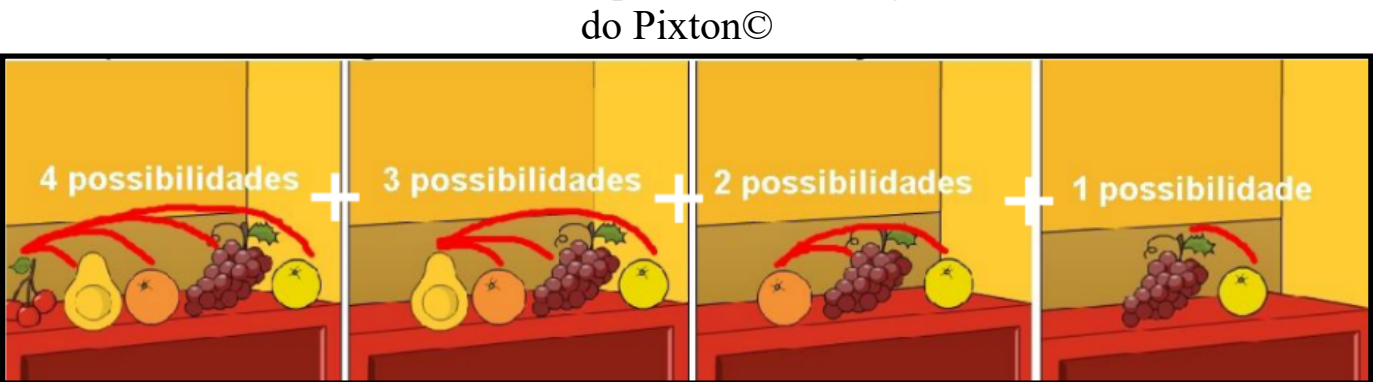

“Situação de combinação - Na barraca Espaço Drinks há cinco frutas (acerola, caju, laranja, limão e maracujá) e os sucos são preparados misturando duas das frutas. De quantas maneiras diferentes os sucos podem ser preparados com as duas frutas?"

Fonte: Gadelha (2020).

Outro detalhe observado foi que os estudantes mesmo não tendo o hábito de manusear equipamentos como o notebook utilizado, e mesmo sendo o primeiro contato com o Pixton(C), não demonstraram dificuldades em realizar a atividade. Essa nova experiência despertou o interesse e a curiosidade de todos os participantes, além do software ser bastante atrativo pela diversidade de ferramentas.

Mediante os diálogos durante as sessões de ensino e a partir dos registros armazenados no Pixton $(\mathbb{C}$, nota-se que os participantes desenvolveram compreensões acerca dos invariantes e propriedades combinatórios - escolha e ordenação dos elementos e esgotamento das possibilidades - conforme solucionavam as questões do teste inicial, tornando-se capazes de justificarem as respostas dadas aos problemas e de identificarem os erros que haviam cometido ao realizarem o teste na primeira etapa da pesquisa.

\section{Teste final}

$\mathrm{Na}$ etapa final os estudantes realizaram um teste com a mesma estrutura do primeiro teste, respondido com lápis e papel e sem o auxílio do Pixton@.

$\mathrm{Na}$ Tabela 2 pode-se observar uma comparação entre as porcentagens de acertos do teste inicial e do teste final, por tipo de situação, e de acordo com a classificação elaborada para a pontuação das respostas.

Observa-se que os resultados do teste final estiveram concentrados em Acerto Parcial IV e/ou Acerto Total em todas as situações combinatórias, sendo muito baixo o percentual de 
respostas incorretas. Desse modo, destaca-se o grande avanço no desempenho dos estudantes após as sessões de ensino.

Tabela 2 - Comparação das porcentagens de acerto no Teste Inicial (I) e no Teste Final (F)

\begin{tabular}{|c|c|c|c|c|c|c|c|c|c|c|c|c|}
\cline { 2 - 13 } \multicolumn{1}{c|}{} & \multicolumn{3}{|c|}{ Incorreta } & \multicolumn{2}{c|}{$\begin{array}{c}\text { Acerto } \\
\text { Parcial I }\end{array}$} & \multicolumn{2}{c|}{$\begin{array}{c}\text { Acerto } \\
\text { Parcial II }\end{array}$} & $\begin{array}{c}\text { Acerto } \\
\text { Parcial III }\end{array}$ & \multicolumn{2}{c|}{$\begin{array}{c}\text { Acerto } \\
\text { Parcial VI }\end{array}$} & \multicolumn{2}{c|}{$\begin{array}{c}\text { Acerto } \\
\text { Total }\end{array}$} \\
\cline { 2 - 13 } & I & F & I & F & I & F & I & F & I & F & I & F \\
\hline A & 75,0 & 8,3 & 4,1 & --- & --- & --- & --- & --- & 20,8 & 50 & 12,5 & 41,6 \\
\hline C & 66,6 & 8,3 & 8,3 & --- & 4,1 & 4,1 & 8,3 & 45,8 & 12,5 & 33,3 & --- & 8,3 \\
\hline P & 58,3 & 4,1 & 26,6 & 12,5 & --- & --- & --- & --- & --- & 58,3 & --- & 25,0 \\
\hline PM & 62,5 & 4,1 & 16,7 & --- & 12,5 & --- & --- & --- & 8,3 & 37,5 & 4,1 & 54,1 \\
\hline
\end{tabular}

Mesmo com a redução das respostas incorretas, na situação de combinação percebeuse que boa parte das respostas resultou em Acerto Parcial III - escolha adequada, ordenação incorreta. Dessa forma, muitos avanços foram observados, mas algumas dificuldades ainda permaneceram.

$\mathrm{Na}$ Figura 10 observa-se que a participante construiu possibilidades a partir da listagem com a letra inicial de cada elemento, mas, mesmo sendo um problema com o total de possibilidades reduzido - seis possibilidades - não houve o esgotamento. É visto que tanto a escolha quanto a ordenação foram considerados, mas não foi percebido que ainda restavam duas possibilidades (A, V, L); (L, A, V).

Figura 10 - Resposta classificada como Acerto Parcial IV no teste final

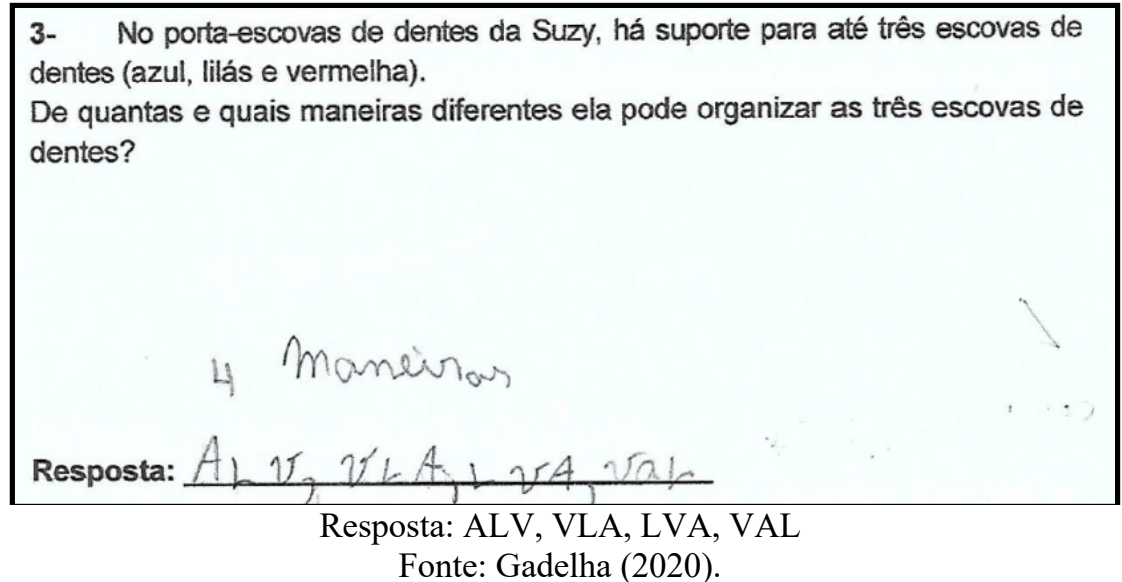

Fonte: Gadelha (2020). 
A falta de sistematização pode ter dificultado a visualização das possibilidades restantes. Com mais tempo de ensino - além de duas sessões - é possível trabalhar explicitamente também essa questão de obtenção de solução de modo sistemático, por exemplo: as permutações iniciadas com A (A, L, V); (A, V, L), seguido das iniciadas em L $(\mathrm{L}, \mathrm{A}, \mathrm{V})$; (L, V, A) e, por fim, as iniciadas em V (V, A, L) e (V, L, A).

Na Figura 11, observa-se um exemplo de um estudante que, mesmo não tendo sido ensinado, sistematizou as possibilidades, de modo que todas foram contempladas.

Figura 11 - Resposta classificada como Acerto Total no teste final

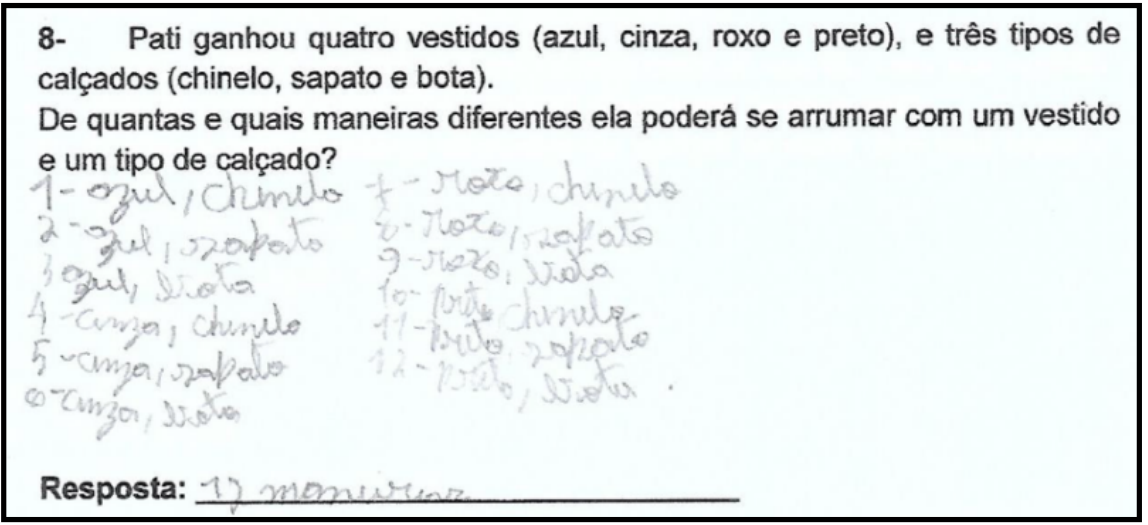

Fonte: Gadelha (2020).

Portanto, para alguns dos participantes as duas sessões de ensino já se mostraram eficazes para que fossem demonstradas percepções para além do ensinado. E mesmo nos casos nos quais não ocorreu o esgotamento das possibilidades, observou-se a melhora na compreensão da Combinatória, quando comparadas as respostas do teste inicial com as do teste final.

\section{Considerações finais}

Os resultados iniciais revelaram que os participantes dessa pesquisa, estudantes do $5^{\circ}$ ano do Ensino Fundamental, detinham poucas compreensões acerca das situações combinatórias. No teste inicial, muitas das respostas não tinham relação com a ideia de agrupar elementos.

A proposta de sessões de ensino com os estudantes em duplas fazendo uso do software Pixton(C) como recurso didático se mostrou bastante eficaz. A ajuda mútua ao longo das resoluções dos problemas e as perguntas norteadoras da pesquisadora se mostraram essenciais para que os estudantes se apropriassem da escolha e da ordenação dos elementos e para o esgotamento das possibilidades nas distintas situações combinatórias. 
Destaca-se ainda que o Pixton(C) se mostrou adequado ao objetivo de ilustrar possibilidades nos diferentes tipos de situações combinatórias - arranjo, combinação, permutação e produto de medidas. É importante ressaltar, também, o número reduzido de possibilidades trabalhadas, sendo de até 12 possibilidades, visto que o intuito era de que os participantes compreendessem as relações combinatórias sem se cansarem.

Pontua-se que mesmo o Pixton(C não tendo sido criado para a finalidade de trabalho com a Combinatória, foi possível utilizá-lo com tal propósito. Assim, as ferramentas desse software podem se tornar um bom recurso para o ensino de Combinatória, em particular nos Anos Iniciais do Ensino Fundamental.

As análises das respostas obtidas no teste final mostraram que os estudantes passaram a demonstrar compreensões combinatórias, sendo contemplados mais acertos parciais e acertos totais para cada tipo de situação. De acordo com a abordagem da Teoria dos Campos Conceituais (VERGNAUD, 1996), percebe-se que tais avanços foram contemplados conforme os estudantes solucionaram as diversas situações combinatórias e a partir das compreensões desenvolvidas sobre invariantes e propriedade em comum - escolha, ordenação e esgotamento de possibilidades - os quais se refletiram diretamente em representações simbólicas mais elaboradas, a exemplo das listagens, e na criação de estratégias mais avançadas, tais como a sistematização na enumeração das possibilidades.

Em linhas gerais, conclui-se a importância da Combinatória ser explorada desde o início da escolarização básica, como também a possibilidade de serem utilizados recursos didáticos, como o Pixton $\mathbb{C}$, que auxiliem no ensino e na aprendizagem deste conteúdo. $\mathrm{O}$ software se mostrou eficaz na ilustração de variadas situações combinatórias e possibilitou que os estudantes de Anos Iniciais do Ensino Fundamental levantassem possibilidades, avançando no desenvolvimento de seus raciocínios combinatórios.

\section{Referências}

AGUIRRE, C. Diagrama de Árbol. Multimídia. 2005.

AZEVEDO, J. Alunos de anos iniciais construindo árvores de possibilidades: é melhor no papel ou no computador? 2013. Dissertação (Mestrado em Educação Matemática e Tecnológica) - Programa de Pós-graduação em Educação Matemática e Tecnológica da UFPE, Recife, 2013.

BORBA, R. O raciocínio combinatório na educação básica. In: X Encontro Nacional de Educação Matemática - ENEM. Salvador, 2010. Anais...Educação Matemática, Cultura e Diversidade. Sociedade Brasileira de Educação Matemática, 2010. 
BRASIL. Secretaria de Ensino Fundamental. Base Nacional Curricular Comum - BNCC. Brasília, 2018.

CHAMORRO, M. C. Didáctica de las Matemáticas para Primaria. Madrid: Pearson Educación, 2003.

GADELHA, D. Resolução de Problemas Combinatórios nos Anos Iniciais: uso de material manipulável concreto (fichas) e de material manipulável virtual (Pixton@). 2020. Dissertação (Mestrado em Educação Matemática e Tecnológica) - Programa de Pós-graduação em Educação Matemática e Tecnológica da UFPE, Recife, 2020.

LEITE, M.; PESSOA, C.; FERRAZ, M.; BORBA, R. Softwares Educativos e Objetos de Aprendizagem: um olhar sobre a Análise Combinatória. Anais... X Encontro Gaúcho de Educação Matemática - X EGEM, Ijuí. 2009.

PESSOA, C.; BORBA, R. Quem dança com quem: o desenvolvimento do raciocínio combinatório de crianças de 1a a 4a série. p.105-150. Zetetiké - Revista de Educação Matemática, Campinas, v. 17, n. 31, dez. 2009.

PIXTON, C. A melhor maneira de criar quadrinhos. Disponível em:

$<$ https://www.Pixton(C.com/br/> Acesso em: 21 out. 2020.

RIVED. Rede Interativa Virtual de Educação. SEED/MEC. Objetos de Aprendizagem Combinação, Permutação, Arranjo, 2008.

SILVA, A. Um estudo exploratório e interventivo sobre conhecimentos iniciais de Combinatória na Educação Infantil in: XXII Encontro Brasileiro de Estudantes de PósGraduação em Educação Matemática. Belo Horizonte, 2018. Anais... do XXII Encontro Brasileiro de Estudantes de Pós-Graduação em Educação Matemática, 2018, p. 1-12.

VERGNAUD, G. A Teoria dos Campos Conceptuais. In: BRUM, Jean (org.). Didáctica das Matemáticas. Lisboa: Horizontes Pedagógicos, 1996. 